\title{
Use of Small-Scale Test Data in Hazard Analysis
}

HAROLD E. NELSON and ERIC W. FORSSELL

Hughes Associates, Inc.

\begin{abstract}
An approach is presented to use small-scale test data to develop rational hazard evaluation of materials as used. The presentation uses the example of fire properties measured or derived from burn tests in the cone calorimeter and uses established relationships to derive the resulting hazard.
\end{abstract}

KEYWORDS: Ignition, flame spread, property measurements, hazard analysis, cone calorimeter

\section{INTRODUCTION}

This paper presents a concept of the use of small-scale test data as the basis of an analytical evaluation of the level of hazard involved in the use of a tested material. The scope of this paper is limited to analysis of the potential of ignition and fire growth involving the use of innovative materials as the skin of aircraft using data developed from the cone calorimeter. The scope of the underlying project is larger and has demonstrated the viability of the approach for external radiant fire propagation and fire development within compartments. Also, the approach has been extended to considerations of toxicity, suppression, and structural integrity.

\section{IGNTTABILTTY}

The ignition process can be treated as the transient heating of a material until a critical surface temperature $\left(\mathrm{T}_{\mathrm{ign}}\right)$ is obtained on the exposed surface. Since flame propagation is to a large extent successive ignition, these same properties have a major impact on flame spread. The value of $T_{i g n}$ varies with the material (as a complex function of the heat of gasification and heat of combustion) and whether there is an external pilot ignition source. The ignition time for a material exposed to a constant heat flux as in the cone calorimeter can be correlated through the following equation [semi-infinite slab] [5]:

$H\left(T_{i g}-T_{0}\right)=\dot{q}_{i}^{\prime \prime}\left(1 .-\exp (a t) \operatorname{erfc}(a t)^{0.5}\right)$

where

$a=\frac{H^{2}}{k \rho c}$

This equation is valid when the material is thermally thick, i.e., the ignition time is less than the thermal penetration time. 
As the ignition time approaches infinity, equation 1 reduces to

$$
\dot{q}_{\text {lgm,min }}=H\left(T_{\text {lgn }}-T_{o}\right)
$$

The use of equation 1 for a material of unknown properties leads to a trial and error fit for $q_{i g n, \min }^{\prime \prime}$ and the parameter a. The methods described here were originally verified experimentally by Quintiere and Harkleroad [6]. Their model of ignition assumes that the material is thermally thick and that heat losses from the sample may be ignored. The material is assumed to heat as a black inert material with constant thermal properties. Given these assumptions, the surface temperature is given by

$T_{s}-T_{0}=\frac{2 \sqrt{t}}{\sqrt{\pi k \rho c}} \dot{q}_{i}^{\prime \prime}$

This expression is taken to hold for thermally thick materials and for all fluxes sufficient to ignite the material; that is, for incident heat fluxes in excess of the critical radiant flux for ignition, $\mathrm{q}_{\text {ign,min }}$

The primary motivation for this approximation is the simplifications it affords in estimating flame spread rates. Caution is needed in applying this approximation to materials that are thin or tested at very low incident fluxes as there is no consideration of asymptotic behavior as expressed equation 1. This can lead to unrealistic solution for applied flux below $q^{\prime \prime}$ ign,min and significant errors in solutions for applied fluxes near $\hat{q}^{\prime \prime}{ }_{i g n, m i n}$. In addition, $\hat{q}^{\prime \prime}$ ign,min, ignition temperature and the parameter a cannot all be simultaneously derived from a curve fit of time and incident flux when using this approximation. Therefore, $\mathrm{q}^{\prime \prime}$ ign,min has to be determined experimentally, with due caution to backside heat losses.

The convective heat transfer coefficient from the flame for a $100 \mathrm{~mm}$ thick upward facing horizontal surface is approximately $10 \mathrm{~W} / \mathrm{m}^{2} \mathrm{~K}$ and approximately $15 \mathrm{~W} / \mathrm{m}^{2} \mathrm{~K}$ for a similar vertical surface. Fortunately, at ignition temperatures, radiative processes dominate, so a precise value for $h_{c}$ is not needed. Therefore, using equation 5 in equation 4 yields

$$
\frac{\dot{q}_{i g n, \min }^{\prime \prime}}{\dot{q}_{i}^{\prime \prime}}=\left[\frac{4 h^{2} t_{i g}}{\pi k \rho c}\right]^{1 / 2}
$$

Plotting the ignition data on a plot of $q_{i g, m i n}^{\prime \prime} / q_{I}^{\prime \prime}$ versus $\sqrt{ } t_{i g}$ yields a straight line of slope, $b$. This can be used to find the effective thermal inertia of the material, $\mathrm{kpc}$, by the equation 4 .

$k p c=\frac{4}{\pi}(h / b)^{2}$

Having determined the ignition temperature and the effective thermal inertia, equation 4 can be rearranged to find the time to ignition under a constant incident heat flux.

$t_{i g}=\left[\frac{T_{i g}-T_{o}}{2 \dot{q}_{i}^{\prime \prime}}\right]^{2} \pi k \rho c$ 
Under variable or transient incident heat flux, the ignition time is defined in a more general form by the following:

$\int_{0}^{t_{8}} \frac{\dot{q}_{i}^{\prime \prime}}{\sqrt{t}} d t=\left(T_{i g}-T_{0}\right) \sqrt{\frac{\pi k p c}{8}}$

Since heat losses are ignored in this model, it is possible for a variable heat flux less than the critical heat flux to "ignite" the composite according to equation 9. Any ignition time found for a flux less than the critical flux should be viewed as an underestimate.

In order to proceed beyond the limits of the thermally thick region, conditions regarding the back side heat losses, etc. must be incorporated. A common assumption is that the back side is insulated. This results in the following equation developed by Kanury [5]:

$$
H\left(T_{i g}-T_{0}\right)=\sum \frac{\dot{q}_{i}^{\prime \prime}\left(1.2 B i \exp \left(-a_{n}^{2} K t / p c l^{2}\right)\right.}{\left(B i(B i+1)+a_{n}^{2}\right)}
$$

$a_{n} \tan \left(a_{n}\right)=B i$

In summary, the ignition temperature, the critical radiant heat flux for ignition, and the effective thermal inertia can be derived from the cone calorimeter. The critical radiant heat flux for ignition is determined experimentally by conducting successive tests to bracket the maximum incident flux incapable of causing ignition and the minimum incident flux that results in ignition. The accuracy of the determination is directly related to the degree that these values are converged to a single value. A significant number of tests may be needed to make an accurate determination. The ignition temperature can be determined using the critical radiant heat flux for ignition in equation 6. By performing a series of experiments at external heat fluxes above the critical radiant heat flux for ignition, a plot of $\dot{q}_{\text {ig,min }}^{\prime \prime} /{ }^{\prime \prime}{ }_{I}$ versus $\sqrt{ } t_{i g}$ can be constructed. The slope, $b$, of the straight line is used in equation 7 to define the effective thermal inertia. Having determined the ignition temperature and the effective thermal inertia, equations 8 and 9 can be used to predict the time to ignition or if ignition will occur at all.

\section{FLAME SPREAD}

Flame spread is the movement of the flame front across the surface of a material that is burning (or exposed to an ignition flame) where the exposed surface is not yet fully involved. Physically, flame spread can be treated as a secession of ignitions resulting from the heat energy produced by the burning portion of a material, its flame, and any other incident heat energy imposed upon the unburned surface. Other sources of incident energy would include another burning object, high temperature gases that can accumulate in the upper portion of an enclosed space, and the radiant heat sources used in a test apparatus such as the cone calorimeter or the LIFT. For analysis purposes, flame spread can be divided into two categories, that which moves in the same direction as the flame (Concurrent or Wind Aided Flame Spread) and that which moves in any other direction (Lateral or Opposed Flame Spread). In this study, the terms concurrent and lateral are used. Concurrent flame spread is assisted by the incident heat flux from the flame back to the burning region and to unignited portions of the burning material. Lateral flame spread is not so assisted and tends to be much slower in progression unless an external source of heat flux is present. Lateral flame spread is of little significance to the problems related to the use of composites in aircraft and is ignored in the hazard analysis examples in this report. Concurrent flame spread can be expressed as 
The values for $\mathrm{k} \rho \mathrm{c}$ and ignition temperature are calculated from the cone calorimeter as discussed in the section on ignition.

\section{HEAT REILEASE RATE-FIRE GROWTH}

Heat release rate is defined as the amount of heat produced from the combustion of a given material at a given time. The heat release rate may be constant with time or may vary with time as is common in the case of accidental fires. The heat release rate from a burning material is a function of both the mass loss rate and heat of combustion of the material. The amount of mass loss over time depends on the applied heat flux to the material. This heat flux can come from the flame generated as the material burns as well as from an external source. In the cone calorimeter, the cone radiator produces an external radiation that can be considered to simulate either the radiant feedback from the type of flame that would occur from a larger specimen, an external heat source or a combination of both.

The heat release rate at the time of an accidental fire cannot be predicted solely from basic measurements of material properties because the mass loss rate depends on the fire environment, the manner in which the material is volatilized, and the efficiency of the vapor combustion [7]. However, pertinent and essential information regarding the potential role of a material in a fire and the size and growth of a fire can be assessed by measuring the heat release rate. The capability of the cone calorimeter of varying the applied flux permits the sample to be exposed to a range of exposure conditions associated with developing fires. It also provides information on when the material may contribute to the fire and the magnitude of that contribution. With these data, it is possible to derive both the heat of gasification, which is a measure of the heat required to vaporize a unit mass of the material, and the generation of gaseous species and smoke.

The heat of gasification is defined by the expression

$$
\dot{G}_{f}^{\prime \prime}=\left(\dot{q}_{i}^{\prime \prime}-\dot{q}_{L}^{\prime \prime}\right) / \Delta H_{g}
$$

While the ratio of the heat absorbed to the mass of fuel gasified is a constant for steady burning of a liquid, in general the heat of gasification is a function of the progress of the decomposition process. Several investigators have made attempts to develop a method of expressing the heat of gasification as a function of a single variable. The choices of variables include the total heat released, the total mass released, or the total energy absorbed up to the point in time under consideration. All of these variables are closely related. The most direct and most studied variable is the total energy absorbed. This variable relates directly to the state of the remaining composite and in principle can respond to differences in the heat lost to the environment. It has been shown that this method will work for charring and noncharring solids of various thicknesses, for both constant and linearly increasing heat flux histories.

The total heat absorbed by a composite, q", is given by

$$
q^{\prime \prime}=\int_{0}^{t} \dot{G}_{f}^{\prime \prime}\left(\dot{q}_{i}^{\prime \prime}-\dot{q}_{L}^{\prime \prime}\right) d t
$$

With $\dot{q}_{L}^{\prime \prime}$ known, it is possible to process all the mass loss rate data.

$$
\Delta H_{g}\left(q^{\prime \prime}\right)=\frac{\dot{q}_{i}^{\prime \prime}-\dot{q}_{L}^{\prime \prime}}{\dot{G}_{f}^{\prime \prime}\left(q^{\prime \prime}\right)}
$$


This expression applied to the mass loss data yields the heat of gasification as a function of the total heat absorbed. Further work is required to develop models of $\Delta \mathrm{H}_{\mathrm{g}}\left(\mathrm{q}^{\prime \prime}\right)$ for different classes of materials so that the function $\Delta \mathrm{H}_{\mathrm{g}}\left(\mathrm{q}^{\prime \prime}\right)$ can be described parametrically.

Having determined $\Delta \mathrm{H}_{\mathrm{g}}\left(\mathrm{q}^{\prime \prime}\right)$ and $q_{\mathrm{L}}$, the mass loss rate from a composite can be determined from $\dot{G}_{f}^{\prime \prime}=\frac{\dot{q}_{I}^{\prime \prime}(t)-\dot{q}_{L}^{\prime \prime}(t)}{\Delta H_{g}\left(q^{\prime \prime}\right)}$

This along with the heat of combustion are used to determine the heat release.

Given the fuel volatilization rate, it is straightforward to determine the heat release rate, the generation rate of gaseous species, and smoke. These quantities are related to the mass loss rate through the following expressions:

$$
\begin{aligned}
& H_{c}=\frac{\dot{q}}{\dot{G}_{f}} \\
& \Psi_{i}=\frac{\dot{G}_{i}}{\dot{G}_{f}}=\frac{Y_{i, \text { exh }} \dot{m}_{\text {exh }}}{\dot{G}_{f}} \\
& \sigma_{m}=\frac{k_{\text {exh }} \dot{m}_{\text {exh }}}{\dot{G}_{f e x h}}
\end{aligned}
$$

$H_{c}, \Psi_{j}$, and $\sigma_{m}$ can be determined as average values or as functions of the total energy absorbed, $q^{\prime \prime}$. These values can then be used in hazard analysis procedures.

\section{HAZARD ANALYSIS FRAMEWORK}

The remainder of this paper describes a hazard analysis framework designed to measure the impact of using materials having flammability properties measured in the cone calorimeter. This analysis is demonstrated through an example comparing the fire behavior of two materials proposed as candidate aircraft wing surfaces. The advantage of evaluating materials on a hazard basis is that it allows the user to assess the impact of the measured fire properties in the context of a proposed application. The results obtained quantify the impact of a material in terms of selected hazard criteria, and the criteria can be varied to address end-use environments and the specific concerns of the user.

An example analysis is presented. The example addresses the application of hazard analysis to a case where the aircraft is exposed to a pool (spill) fire. (JP-4 pool fires between 0 and $8 \mathrm{~m}$ (up to $26 \mathrm{ft}$ ) in diameter are evaluated.)

For this example, it was assumed that the aircraft of interest has a wing where the underside surface is made of the candidate material. Two hypothetical synthesized materials are examined. In addition, PMMA and pine are used as reference points, the baseline of comparison being an aircraft constructed of noncombustible material (e.g., aluminum).

The material surface presents a panel $10 \mathrm{~m}$ wide at the connection with the fuselage and extends $20 \mathrm{~m}$ from the fuselage. There is a taper; the total area of the composite is $150 \mathrm{~m}^{2}\left(1614 \mathrm{ft}^{2}\right)$. This very large wing surface was arbitrarily selected to show the impact and the differences between one material and another. The wing stands $2 \mathrm{~m}(6.6 \mathrm{ft})$ above the ground when the 
aircraft is at rest. The exposing fire is defined as a pool (spill) fire of JP-4 or similar fuel located directly under the midpoint between the fuselage and the end of the wing. In terms of flame spread and fire development, this is a worst case analysis.

The results of the hazard analysis can be presented in two forms. The first form would be aimed at the pragmatic and practical needs of the firefighter, with information presented in terms of comparisons to items or conditions for with which the firefighter is already familiar. Examples of such reference points include diameters of pool fires, potential of ignition of wood or plastic materials, and thresholds of pain. The second form would be in terms of engineering data for those interested in a detailed analytical analysis such as aircraft designers or new material developers.

(1) Step 1. Relating pool fire size to fire exposure intensity. Persons experienced in aircraft firefighting understand the impact of fire if expressed in terms of the size of a pool (or spill) fire. Conversely, energy release rate terms do not connote meaningful information to them. Since almost all of the engineering relationships involved in analyzing fire hazards are based on energy release rates, it is necessary correlate fire diameter and rate of (heat) energy release be developed and used in the method. This involves consideration of both the rate of mass burning and the heat of combustion of the fuel. The equations used were those presented by Babrauskas [8].

$$
\begin{aligned}
& \dot{m}=\dot{m}_{a}\left(1-e^{-k b D}\right) \\
& \dot{q}=h_{c} \dot{m}^{\prime \prime} A
\end{aligned}
$$

(2) Step 2 Determination of the extent and intensity of exposure to the candidate material from the exposure fire as a function of the exposure fire size (i.e., wing surface exposure from various diameter pool fires). For this step in the analysis, a correlation developed by Alpert for a flow of hot gases and flame on a ceiling as a function of the fire size [9] was used.

$$
r=\dot{q}\left(\frac{6.87}{z / T^{3 / 2}}\right)
$$

Figure 1 plots the results for pool fire diameters up to $4 \mathrm{~m}(26 \mathrm{ft})$ in diameter at which the temperature would be $400,500,600$, and $700^{\circ} \mathrm{C}$. These temperatures are used as surrogates for heat flux levels of $<25 \mathrm{~kW} / \mathrm{m}^{2}, 25 \mathrm{~kW} / \mathrm{m}^{2}, 50 \mathrm{~kW} / \mathrm{m}^{2}$, and $75 \mathrm{~kW} / \mathrm{m}^{2}$, respectively.

(3) Step 3. Determination of minimum size fire needed to ignite candidate material in manner used in specified aircraft. This step uses McCaffrey's equation [10] to determine the minimum size pool fire necessary to ignite the composite material. This is done by relating the assumed flux (as discussed in Step 2 above) to the calculated temperature and comparing this to the results obtained in the cone calorimeter.

$\dot{q}_{c}=\left(0.449 \mathrm{zg}\left(T_{f}-T_{a}\right) / T_{a}\right)^{5 / 2}$

(4) Step 4. Calculate the contribution of the candidate material to fire size. Step 4 initiates the calculation of specific information to be presented in the normal output of the hazard analysis system. This step calculates the change in fire size due to the introduction of the candidate material.

From the cone calorimeter test, determine minimum ignition energy, ignition temperature, rate of heat release at various fluxes, and the effective thermal inertia $(\mathrm{k} \rho \mathrm{c})$. 
Use the FLSPREAD model [11]. This model provides information on the time involved for the fire to spread and the rate of heat per unit area exposed. The fundamental equations used in this FLSPREAD model are as indicated below.

$$
\begin{aligned}
& t_{i g n}=\frac{\pi k p c\left(T_{i g n}-T_{s}\right)^{2}}{\left(4 \dot{q}_{f}^{\prime \prime}\right)^{2}} \\
& d=\frac{0.01 \dot{q}_{r}^{\prime \prime}+1}{0.01 \dot{q}_{r}^{\prime \prime}} e^{0.014_{r} t_{m}}-\frac{1}{0.01 \dot{q}_{r}^{\prime \prime}} \\
& Y_{f}=Y_{o} d+Y_{o} \\
& A_{f}=Y_{f} X_{o}
\end{aligned}
$$

In applying this model, it is assumed that the flux from the burning flame produced by the candidate material will always be in the range of approximately $25 \mathrm{~kW} / \mathrm{m}^{2}$. For the purposes of these calculations, it is therefore assumed that if the material has a critical incident flux as measured in the cone calorimeter of $25 \mathrm{~kW} / \mathrm{m}^{2}$ or less, the flame will extend to the end of the wing. The FLSPREAD model indicates the time that this takes to occur. Conversely, if the critical ignition flux is higher than $25 \mathrm{~kW} / \mathrm{m}^{2}$, it is assumed that the flame spread extends only to the extent that the pool fire imposed a heat flux on the wing equalling or exceeding the 50 $\mathrm{kW} / \mathrm{m}^{2}$ necessary to produce continued burning in this material. The impacting flux is determined on the basis of the temperature profiles developed using the Alpert correlations in Step 3.

There are two additional inherent, conservative assumptions involved in the flame spread evaluation.

(a) It is assumed that the material involves is thick enough to continue burning and impose flux ahead of the flame front for a sufficient amount of time to assure ignition.

(b) It is also assumed that there is no impact on flame spread in the long dimension of the target (wing) as a result of energy vented by hot gases and/or flame spilled from the edges of the wing.

The implementation of the flame spread calculations requires the provision of parameter values for heat release rate, flame extension, ignition temperature, and thermal inertia. These are derived from cone calorimeter data as follows:

Heat Release Rate: Heat release rate is measured in the cone calorimeter using the oxygen depletion method. A distinct value for heat release rate (in $\mathrm{kW} / \mathrm{m}^{2}$ ) is developed for each level of incident flux used. For this analysis, values were established for each of the materials considered at 25,50 and $75 \mathrm{~kW} / \mathrm{m}^{2}$.

Flame Extension: Determination of flame extension is necessary to determine the extent of incident flux from that portion of the flame in contact with the candidate material to that material and the length of the flame extension beyond the portion of the candidate material that is actually burning. The following equations are used. 
For extension in the vertical direction or in the direction of the flow of the flame (as under a wing), equation 23 is rearranged to solve for $z$ (height over flame source) for the heat release rate of interest. The rearranged equation is as follows:

$z=\frac{\dot{q}_{c}^{2 / 5} T_{a}}{0.449 g\left(T_{f}-T_{a}\right)}$

Modak's correlation [12] is used for lateral extension from a burning pool or similar fire with a lateral dimension (as opposed to the thin sheet of flame extending from an advancing flame front).

$\dot{q}_{t}^{\prime \prime}=\frac{\dot{q}}{4 \pi r^{2}}$

The conversion of flame temperature results from equation 28 to incident flux, assuming contact between the flame and the target, is done with the following heat transfer expression.

$\dot{q}_{f}=h_{c}\left(T_{f}-T_{a}\right)+\sigma\left(T_{f}^{A}-T_{a}^{A}\right)$

Thermal Inertia and Ignition Temperature: The determination of ignition temperature and thermal inertia $(\mathrm{k \rho c})$ are interrelated by equations 6 and 7. These equations are appropriate for thermally thick materials and loose accuracy if there is significant temperature loss from the back side of the specimen. To minimize this error, the time to ignition was taken from cone calorimeter tests with an incident flux of $75 \mathrm{~kW} / \mathrm{m}^{2}$. At this higher flux, the experiential time to ignition tends to be quite short and minor variations in reading the data can have a measurable effect on the ensuing calculations.

Tables 1 and 2 list the values obtained or derived from cone calorimeter tests are used in this example.

TABLE 1. AVERAGE MAXIMUM HEAT RELEASE RATES $\left(\mathrm{kW} / \mathrm{m}^{2}\right)$

\begin{tabular}{||l|l|c|c|c|}
\hline \multirow{2}{*}{ Material } & \multirow{2}{*}{$\begin{array}{c}\text { Sample } \\
\text { Orientation }\end{array}$} & \multicolumn{3}{c|}{ Externally Applied Heat Flux } \\
\cline { 3 - 5 } & & $25 \mathrm{~kW} / \mathrm{m}^{2}$ & $50 \mathrm{~kW} / \mathrm{m}^{2}$ & $75 \mathrm{~kW} / \mathrm{m}^{2}$ \\
\hline \hline \multirow{3}{*}{ PMMA } & Horizontal & 650 & 900 & 1300 \\
\cline { 2 - 5 } & Vertical & 560 & 720 & 1300 \\
\hline \multirow{2}{*}{ Pine } & Horizontal & 140 & 240 & 265 \\
\cline { 2 - 5 } & Vertical & 130 & 170 & 240 \\
\hline Candidate 1 & Horizontal & 125 & 200 & 250 \\
\cline { 2 - 5 } & Vertical & 90 & 130 & 220 \\
\hline Candidate 2 & Horizontal & & 215 & 250 \\
\cline { 2 - 5 } & Vertical & & 165 & 170 \\
\hline
\end{tabular}


TABLE 2. IGNITION AND FLAME SPREAD RELATED VALUES

\begin{tabular}{||l|c|c|c|c|}
\hline \hline Material & $\begin{array}{c}\text { Pilot } \\
\text { Ignition } \\
\text { Temperature } \\
\left({ }^{\circ} \mathrm{C}\right)\end{array}$ & $\begin{array}{c}\text { Critical Flux } \\
\text { for Ignition } \\
\left(\mathrm{kW} / \mathrm{m}^{2}\right)\end{array}$ & $\begin{array}{c}\text { t (ignition) } \\
\left(\text { at } 75 \mathrm{~kW} / \mathrm{m}^{2}\right)\end{array}$ & $\begin{array}{c}\text { Thermal Inertia } \\
\left(\mathrm{W}-\mathrm{J} / \mathrm{m}^{4}-\mathrm{K}^{2}\right)\end{array}$ \\
\hline \hline PMMA & 275 & 10 & 12 & 1.32 \\
\hline Pine & 383 & 7 & 6 & 0.3 \\
\hline Candidate 1 & 450 & 24 & 20 & 0.77 \\
\hline Candidate 2 & 575 & 40 & 33 & 0.77 \\
\hline
\end{tabular}

The total rate of heat release produced by the candidate material is then added to that produced by the pool fire. The results are shown in Figure 2. The jump shown in the range of slightly less than $1 \mathrm{~m}$ pool fire diameter is indicative of the point at which the pool fire flame imposes an ignition temperature on the wing, and the fire then spreads rapidly to the end of the wing. The time function is not shown on this graph, but derived for each of the individual items.

\section{CONCLUSIONS}

The capability of rational development of the hazard impact of materials based on properties measured in or derived from small (bench) scale test as a viable and useful tool for the application of fire science to the fire problem has been demonstrated. There are, of course, limitations and needs for improved data and improved understanding of important aspects of fire phenomena, but worthwhile analysis can now be made using existing tests procedures to measure fire phenomena and existing analytical expressions to predict the response of materials to such phenomena. Important to the advance of techniques such as those described in this paper is a continued program of full- and bench-scale test to improve the accuracy of correlations such as those used herein.

\section{REFERENCES}

1. Kanury, A.M., "Ignition of Cellulosic Materials: A Review," Fire Research Abstracts and Reviews, 14, 1972.

2. Kashiwagi, T., "Effects of Attenuation of Radiation on Surface Temperature for Radiative Ignition," Combustion Science and Technology, 20, 1979.

3. National Materials Advisory Board, "Fire Safety Aspects of Polymeric Material, Aircraft: Civil and Military," Publication NMAB 318-6, Washington, DC, 1977.

4. Rasbash, D.J., "The Extinction of Fire with Plain Water: A Review," Fire Safety Science-Proceeding from the First (International) Symposium, Hemisphere Publishing, 1986.

5. Kanury, A.M., "Flaming Ignition of Solid Fuels," SFPE Handbook of Fire Protection Engineering, DiNenno, P.J., ed., National Fire Protection Association, Boston, MA, 1988. 
6. Quintiere, J.G, and Harkleroad, M., "New Concepts for Measuring Flame Spread Properties," NBSIR 84-2943, National Bureau of Standards, Gaithersburg, MD, 1984.

7. Cote, A.E. and Linville, J., ed., Fire Protection Handbook, 16th edition, National Fire Protection Association, Quincy, MA, 1986.

8. Babrauskas, V., "Burning Rates," SFPE Handbook of Fire Protection Engineering, DiNenno, P.J., ed., National Fire Protection Association, Boston, MA, 1988.

9. Alpert, R.L., "Calculation of Response Time of Ceiling-Mounted Fire Detectors," Fire Technology, 8 (3), 1972, pp. 181-195.

10. Drysdale, D.D., An Introduction to Fire Dynamics, John Wiley and Sons, Chichester, England, 1985.

11. Nelson, H.E., "A Simple Model for Surface Flame Spread," (in preparation).

12. Modak, A.T., "Thermal Radiation from Pool Fires," Combustion and Flame, 30, 1977, pp. 252-265. 


\section{NOMENCLATURE}

$\mathrm{a}=\mathrm{a}$ constant appox. $=$ to $\mathrm{H}^{2} / \mathrm{k} \rho \mathrm{c}$

$A=$ area of pool fire $\left(\mathrm{m}^{2}\right)$,

$a_{n}=$ roots of equation 11

$A_{s}=$ surface area of space $(\mathrm{m})$

$\mathrm{b}=$ slope of line plotted as described

$\mathrm{Bi}=$ Biot Number $h_{c} l / K$

$\mathrm{c}=$ specific heat

$\mathrm{d}=$ proportional advance of flame front in terms of current area of involvement

$\mathrm{D}=$ diameter of the pool fire $(\mathrm{m})$

$d_{f}=$ distance center of fire to target

$\mathrm{f}_{\mathrm{L}}=$ flame length

$\mathrm{g}=$ acceleration due to gravity

$\mathrm{G}_{\mathrm{f}}^{\mathrm{n}}=$ vapor mass generation rate

$\mathrm{h}=$ overall heat transfer coefficient

$\mathrm{H}=$ combined convective and linearized radiative heat transfer coefficient

$h_{c}=$ convective heat transfer coefficient

$\mathrm{H}_{\mathrm{c}}=$ heat of combustion

$\mathrm{K}^{\mathrm{c}}=$ thermal conductivity

$\mathbf{k}_{\mathrm{exh}}=$ measured extinction coefficient in the exhaust

$\mathrm{k} \rho \mathrm{c}=$ thermal inertia

$1=$ thickness

$\mathrm{In}^{\prime \prime}=$ mass burning rate per unit area $\left(\mathrm{kg} / \mathrm{m}^{2} \mathrm{~s}\right)$

$Q=$ rate of heat release of source fire $(\mathrm{kW})$

$\mathrm{q}_{\mathrm{c}}{ }^{\prime \prime}=$ radiant flux on target $\left(\mathrm{kW} / \mathrm{m}^{2}\right)$

$\mathrm{h}_{\mathrm{a}}=$ mass burning rate for an infinite diameter pool of specified fuel $\left(\mathrm{kg} / \mathrm{m}^{2} \mathrm{~s}\right)$ - (0.39 for JP-4 and 0.51 for JP-5)

I $_{\text {exh }}=$ measured exhaust rate

$\mathrm{q}^{\prime \prime}=$ total heat absorbed

$\mathrm{q}^{*}=$ incident flux from the flame above the unignited surface to that surface back (normally assumed to be approximately $20 \mathrm{~kW} / \mathrm{m}^{2}$ )

$q_{c}=$ convective portion of the rate of heat release in $\mathrm{kW}$ (assumed to by $60 \%$ of the total rate of heat release for these calculations)

$q_{f}{ }^{\prime \prime}=$ flux from flame extension to surface $\left(\mathrm{kW} / \mathrm{m}^{2}\right)$

$\mathrm{q}_{\mathrm{i}}{ }^{n}=$ incident heat flux

$\mathrm{q}_{\text {ign,min }}=\quad$ critical radiant flux for ignition

$q^{m}=$ heat loss

$\mathrm{q}_{\mathrm{r}}{ }^{\prime \prime}=$ average rate of heat release of ignited material $\left(\mathrm{kW} / \mathrm{m}^{2}\right)$

$q_{t}{ }^{n}=$ incident flux on exposed (target) material ( $\left.\mathrm{kW} / \mathrm{m}^{2}\right)$,

$r=$ radial distance $(\mathrm{m})$ from point directly over center of fire where hot gases will be at $\mathrm{T}$ (degrees $\mathrm{K}$ ) above ambient $r=$ radial distance from center of fire to target (fire center is considered to be actual center or $0.5 \mathrm{~m}$ from nearest point of fire to target, which ever is least)

$\mathrm{t}=$ time

$\mathrm{T}=$ temperature increase $(\mathrm{K})$ at point $\mathrm{r}$

$\mathrm{T}_{\mathrm{f}}=$ flame temperature at height $\mathrm{z}$ over fire source $(\mathrm{K})$

$t_{p}=$ thermal penitration time

$t_{\mathrm{ig}}^{\mathrm{p}}=$ time to ignite at incident flux

$t_{\text {pign }}=$ time since ignition/time to ignite

$\mathrm{T}_{\mathrm{ig}}=$ ignition temperature

$\mathrm{T}_{\mathrm{o}}^{\mathrm{ig}}=$ ambient temperature

$\mathrm{T}_{\mathrm{s}}^{\mathrm{o}}=$ surface temperature

$\mathrm{T}_{\mathrm{s} \text {,ign }}=$ surface temperature at ignition

$\mathrm{V} \stackrel{\text { sign }}{=}$ flame spread velocity

$X_{0}=$ width of initial area of involvement (m)

$\mathrm{X}_{\mathrm{I}}=$ radiant fraction

$Y_{\mathrm{f}}=$ length of burning surface (m)

$Y_{i ; \text { exh }}=\quad$ mass fraction of species $i$ in the

$Y_{0}=$ length of initial area of involvement (m)

$z=$ height over fire source (m)

$\sigma=$ Steffen-Boltzmann constant

$\sigma_{\mathrm{m}}=$ specific extinction area

$\Delta \mathrm{H}_{\mathrm{g}}=$ heat of gasification

$\rho=$ density

$\psi_{i}=$ mass fraction of species $i$ 


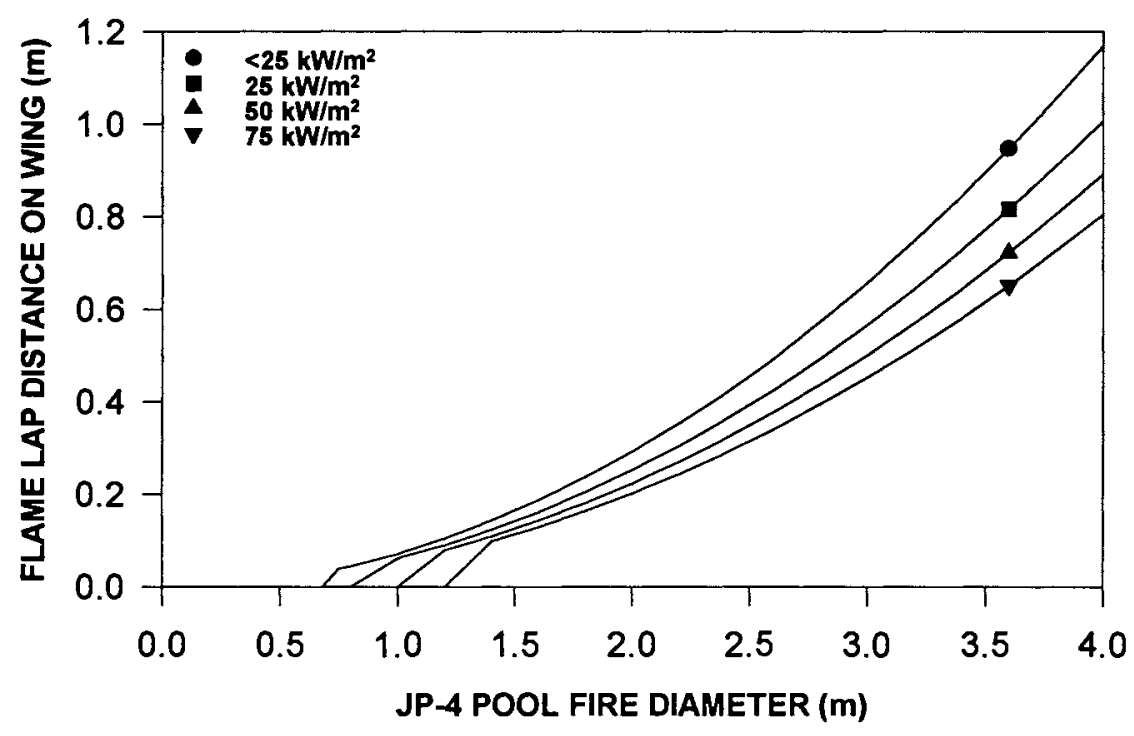

Figure 1. Flame Contact Extent on Underside of Aircraft Wing Located $2 \mathrm{~m}$ Above Pool Fire

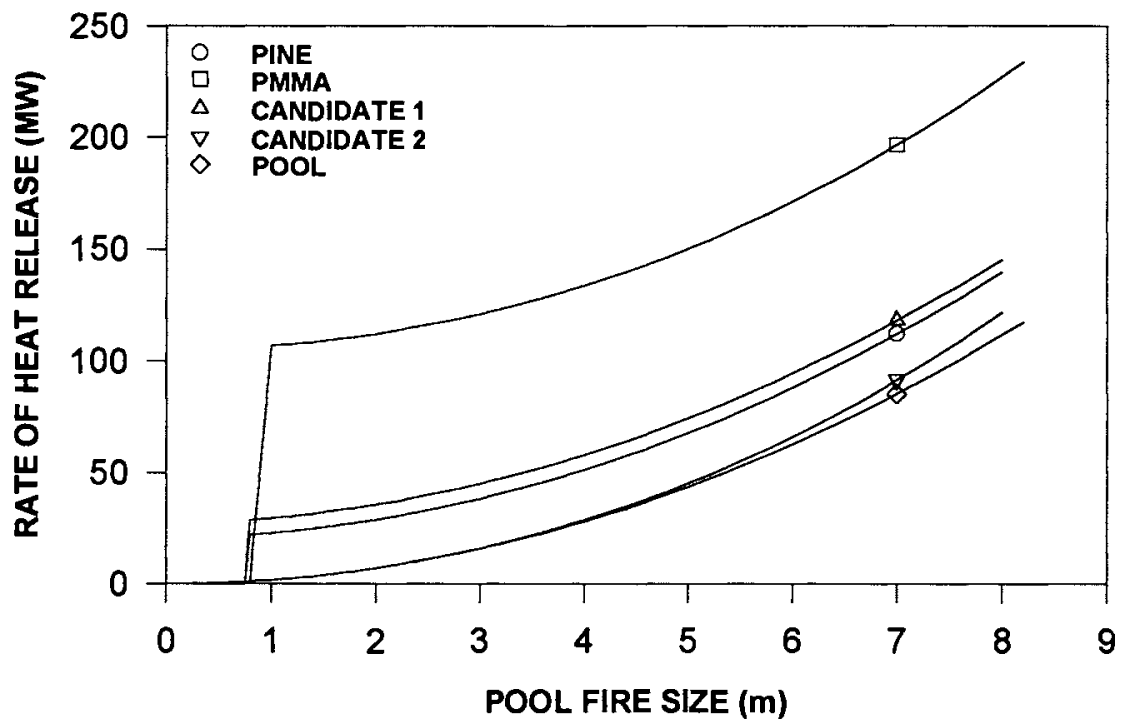

Figure 2. Effect on Rate of Heat Release on Different Material Types 